\title{
Sciendo
}

Administration, vol. 69, no. 4 (2021), pp. 151-160

doi: 10.2478/admin-2021-0032

\section{Strategic policy committees: Talking shops or active participants in local policy development?}

\author{
Fintan Phelan \\ Carlow County Council, Ireland
}

\section{Introduction}

This paper will examine the strategic policy committee (SPC) in Ireland. In response to a widespread desire for reform of local government and a desire for more participatory forms of government, Ireland introduced the SPC into local government. This paper will examine this committee, its origins and the elements of the policymaking cycle it encompasses. Firstly, the paper will examine the background to the introduction of SPCs, their legislative basis and what they are envisaged to do. The paper will then look at the SPC in practice, including the agenda and minutes of several SPCs across the country, along with academic articles and news reports. It will examine some of the challenges that are facing the SPC and then finally outline possible solutions to enhance the participation of SPCs in local policy development.

\section{Reform agenda and legislative basis of SPCs}

The system of local government in Ireland dates back to the Local Government (Ireland) Act, 1898. This act 'established the county as the principal administrative unit and the elected county council as the 
means of administering local government' (Forde, 2005, p. 137). Following independence this system was retained and continued to be further centralised by national government, and unelected county managers possessed the bulk of the decision-making powers that remained at local government level, including drawing up the annual budget (Forde, 2005, p. 138). This system of local government has been described as "not particularly responsive to the needs of communities at local level' and as 'a serious case of politicoinstitutional underdevelopment and maldevelopment' (Forde, 2005, p. 137; Barrington, 1993, p. 6). Quinn notes that the 'deficiencies in the Irish system were well documented' (Quinn, 2007, p. 4). These criticisms of the system led to a push for reform in Ireland's system of local government. In 1996 a White Paper, Better Local Government, was published which proposed an enhancement in the policy role of local councillors. The Local Government Act, 2001, put this on a legislative basis, introducing strategic policy committees (SPCs) in local authorities. According to Quinn (2007, p. 8), 'The SPCs represent a new way of working for all concerned - a formal role for sectoral nominees who previously operated outside the institutions of local government; a shift in focus to policy making as well as a sharing of jurisdiction for elected representatives and a move to facilitative rather than techno-authoritative approaches for local authority personnel'.

In considering whether SPCs are active participants in local policy development it is necessary to consider the policymaking cycle. Hague \& Harrop (2010, p. 370) set out five key stages in the policymaking cycle: 'initiation, formulation, implementation, evaluation, and review.' Policy initiation and formulation are described as being about 'the decision to make (or reverse) policy in a particular area and then to develop specific proposals within that area' (Hague \& Harrop, 2010, p. 371). In theory, SPCs have a policy initiation and formulation role. Section 48 of the Local Government Act, 2001, sets this out by stating that SPCs are committees to "consider matters connected with the formulation, development, monitoring and review of policy' related to the function of a council and to 'advise the authority on those matters'. Similarly, ministerial guidelines published in 2014 governing the establishment and operation of SPCs make clear that SPCs should provide a more 'visible and effective role in policy setting' for councillors (Department of Housing, Local Government and Heritage, 2014). These guidelines make clear that policy initiation and formulation are part of the remit of SPCs as they would 'prepare the groundwork for policies' and provide a 'better focus and enhanced 
capacity for involvement in policy formulation' (Department of Housing, Local Government and Heritage, 2014). Each local authority is required to adopt an SPC scheme at the start of each five-year term. This scheme covers the operation guidelines of the SPC. Examining many of these schemes makes it clear that the SPC has a policy initiation and formulation role. The SPC scheme of Louth County Council states that 'A critical element of public policy formulation by the SPC is the availability to the local authorities of expertise, skills and knowledge from persons outside of the public service' (Louth County Council, 2019). Meath County Council's scheme states that 'SPCs will function as policy centred committees, which can harness the experience of external bodies in the formulation of policy' (Meath County Council, 2019). The legislation establishing SPCs, ministerial guidelines on their operation, and local authorities' own SPC schemes make it clear that, in theory, SPCs have a key role in policy initiation and formulation.

Policy implementation is described as 'putting policy into effect' and the 'execution' of policy (Hague \& Harrop, 2010, p. 372). There are two approaches to policy implementation: the 'top-down' approach and the 'bottom-up' approach. The top-down approach is described as the 'traditional view of implementation' whereby a policy is formulated at national level and all levels of administration underneath are expected to implement the policy; however, this approach has been described as focusing 'excessively on control and compliance' (Hague \& Harrop, 2010, p. 371). The bottom-up method notes that 'policy-makers should seek to engage rather than control those who translate policy into practice' (Hague \& Harrop, 2010, p. 372). In line with this approach, 'many policy analysts now suggest that objectives are more likely to be met if those who execute policy are given not just encouragement and resources but also flexibility' (Hague \& Harrop, 2010, p. 373). In summary, Hague \& Harrop (2010, p. 372) state that 'A top-down approach conceives the task of policy implementation as ensuring that policy execution delivers the outputs and outcomes specified by the policy-makers. By contrast, a bottomup approach judges that those who execute policy should be encouraged to adapt to local and changing circumstances.' In theory, by including sectoral interests on SPCs, policy implementation should be more adaptable to changing and local circumstances. Various local groups on SPCs should be able to feed into the SPC on the implementation of that policy and how to adapt it to local needs. The language in the ministerial guidelines about an 'inbuilt assistance from 
sectoral interests' certainly gives credence to this (Department of Housing, Local Government and Heritage, 2014). As Quinn (2007, p. 10) describes, there is an attempt with the SPC system to 'move nongovernmental actors from passive acquiescence to active involvement through consultation and sectoral representation'. Indeed SPCs should reflect a 'bottom-up approach' to policy implementation.

The aim of policy evaluation is 'to work out whether a programme has achieved its goals and if so how cost effectively' (Hague \& Harrop, 2010, p. 373). Hague \& Harrop (2010, p. 373) describe how policy goals can be 'modified during implementation', which, according to Fesler and Kettl (2008, p. 287), leads to a 'mushiness of goals'. This in turn 'means that policy-makers' intent is often a poor benchmark for evaluation' (Hague \& Harrop, 2010, p. 373). Hague \& Harrop (2010, p. 374) distinguish between policy outputs and policy outcomes, with outputs being 'easily measured by quantitative indicators of activities: visits, trips, treatments, beneficiaries'. Hague \& Harrop (2010, p. 374) state that the danger with focusing on policy outputs is that the 'outputs turn into targets; the focus becomes what was done rather than what was achieved'; it is therefore felt that 'outcomes - the actual results - should be a more important component of evaluation than outputs'. Policy review would normally occur after a policy has been evaluated and there are three options: 'to continue, to revise or to terminate' (Hague \& Harrop, 2010, p. 374). In theory SPCs have a role to play in the evaluation and review of policy. Section 48 of the Local Government Act, 2001, states that SPCs should consider the 'monitoring and review' of policy. The ministerial guidelines also set out a role for SPCs in the 'review and evaluation' of policy (Department of Housing, Local Government and Heritage, 2014).

It is clear that, in theory, the SPC structure is a significant change in policymaking in Ireland and, as set out in legislation, guidelines and schemes, one which allows councillors and sectoral interests 'full involvement in the policy making process from the early stages, when policy options are more fluid' (Department of Housing, Local Government and Heritage, 2014). However, this paper will argue that, in practice, the SPC system is falling short of 'full involvement' in the policymaking cycle.

\section{Key challenges}

The establishing legislation, operational guidelines and SPC schemes all identify that SPCs should allow for 'full involvement' in the 
policymaking cycle. However, there are a number of challenges encountered by SPCs that make this difficult.

The first challenge is the conflict between elected members and sectoral interests. Research has indicated 'that an uneasy relationship exists between councillors and voluntary and community representatives at SPC meetings' (Forde, 2005, p. 141). Elected members can feel that their role is diminished by the inclusion of 'nonelected' sectoral representatives. Indeed Callanan (2005, p. 914) argues that in many cases of participative structures elected politicians can feel 'marginalized'. He notes, 'in particular, elected politicians may perceive such structures as a threat to their traditional role, and may see their position being devalued or marginalized through the process' (Callanan, 2005, p. 914). Community representatives, on the other hand, have felt that they are not treated as equal partners on SPCs (Gannon, 2014). This resulted in them feeling 'left out of things' (Gannon, 2014). Conflict between elected representatives and sectoral interests from the get-go hampers the policy input an SPC can have.

The second challenge that SPCs face is a lack of engagement from sectoral interests, elected members and officials. Quinn has noted that there are 'differing levels of engagement among partners' (Quinn, 2007, p. 7). In many instances there has been 'poor attendance of SPC members' (Callanan, 2005, p. 925). Sectoral interests in some cases do not attend 'unless an issue directly relevant to their constituency was on the agenda' (Callanan, 2005, p. 925). This is not surprising given that in many cases 'there is a perception that SPC meetings can amount to talking shops and a view that there is a need to focus on concrete results' (Callanan, 2005, p. 925). Sectoral representatives have also 'felt intimidated by the jargon and the range of technical documentation with which they are required to familiarise themselves' (Quinn, 2007, p. 11). The weighting in favour of elected members on SPCs and the requirement for the chairperson to be an elected member have led to sectoral interests feeling that their 'degree of influence' is limited (Quinn, 2007, p. 10). These issues hamper the policymaking role of SPCs. If we consider policy implementation, in theory, the inclusion of sectoral interests on SPCs reflect a bottom-up approach to policy implementation, where 'policy-makers should seek to engage rather than control those who translate policy into practice' (Hague \& Harrop, 2010, p. 372). However, 'feeling intimidated by the jargon and range of technical documentation', feeling 'left out' and exercising little influence over the process all lead to disengagement from the process and thus a weakening of the policy involvement of SPCs. 
Finally, a key challenge to the 'full involvement' of SPCs in the policymaking process is the relationship between the centre and the local. Local government in Ireland has very little control over policy and is primarily a policy taker from central government. Indeed Forde $(2005$, p. 145) has argued that 'strengthening elected local government is unlikely to be achieved, however, within a context in which local government has little power and few functions, in which elected local representatives are rarely consulted on national policy, and in which many of them appear reluctant to share what power they have with local communities'. Quinn (2007, p. 11) too has argued that 'neither the functions nor the financial dependence of local government have been significantly changed nor have wider powers or responsibilities been granted to local authorities'. Local government's lack of control in making policy means that the power SPCs have to make policy is 'fundamentally limited' (Forde, 2005, p. 141). This lack of power to formulate policy is clear when one examines SPC agendas and minutes. In the minutes of an Infrastructure Policy, Transportation, Fire and Emergency Services SPC meeting the only example of policy formulation appears in matters arising in relation to the fire safety plan of the council (Kilkenny County Council, 2016). Similarly, the agenda of an Economic Development \& Enterprise SPC had six items on its agenda, excluding minutes, matters arising, AOB and date of next meeting. Of the six remaining items, five were presentations, updates on events or reports (Dublin City Council, 2020). The minutes of a Planning and Building Control SPC meeting included no policy implementation or initiation but a large number of operational reports of the council, and a subsequent meeting of the same SPC saw one policy item in relation to the preparation of a submission to a spatial plan for a regional assembly; it would be a stretch to say the preparation of a submission would be 'full involvement' in the policymaking cycle (Wexford County Council, 2018, 2019). The above SPCs are examples, and the experience of this writer is that there are elements of SPCs' work that allow for policy involvement; however, it is very limited by the constraints placed on it by central government. A director of service in a local authority gave this credence when he stated 'the title strategic policy committee may be a bit misleading for some people, in that we don't make much strategic policy, a lot of what we do is working within the constraints that have been laid down by government policy, which we have to follow' (Gannon, 2014). However, the establishing legislation and operational guidelines are very clear in that SPCs would 'prepare the groundwork for policies' and provide a 'better focus and enhance capacity for involvement in 
policy formulation' (Department of Housing, Local Government and Heritage, 2014). Without a clear policy role for local authorities in the first instance, it is difficult to see how SPCs can allow a 'full involvement' in the policymaking cycle.

\section{Recommendations}

It is important to acknowledge that, in many instances, there have been positive outcomes to the establishment of SPCs. Quinn (2007, p. 8) has noted that 'despite initial wariness by members, the SPC structures have led to a positive relationship between the various sectors involved'. This is not withstanding several challenges outlined above. However, Callanan (2005, p. 925) has put it well when he says 'these difficulties should not imply that participation is a bad thing. Rather, it is important to acknowledge problems with participation, as well as possible unintended consequences.' This paper has outlined a number of those challenges and will now suggest some solutions to make SPCs more in tune with their founding principles of involvement in policymaking.

\section{Training for SPC members}

The operational guidelines for SPCs note that 'training programmes would be valuable for SPC members' and that training for 'effective meeting skills would be useful for SPC chairs and training on policy areas would be significant for all SPC members' (Department of Housing, Local Government and Heritage, 2014, p. 13). As outlined by Quinn (2007, p. 11), many SPC members 'felt intimidated by the jargon and the range of technical documentation with which they are required to familiarise themselves'. Without question SPC members would benefit from training and it should be provided at the start of one's term on an SPC, with specific training then issued as required. Training of SPC members together will also allow for both elected and sectoral interests to collaborate and familiarise themselves with one another, thus enhancing cooperation and breaking down the feeling of 'them and us' that exists in some SPCs. It is clear that the training of SPC members will equip them better to contribute to the policymaking process and should happen in every local authority.

\section{Utilise existing legislation}

As described above, local authorities have few formal powers compared to central government. However, there are mechanisms in 
existing legislation that could be utilised effectively by SPCs. The Local Government Act, 2001, as amended, states that 'for the purposes of assisting a strategic policy committee in considering matters' of policy 'the committee may request the attendance of a public authority at a meeting of the committee' (s. 48 (3A)(a)). If the public authority refuses to attend, the SPC can trigger a mechanism of reporting to both the plenary council and to the minister responsible if the council so wishes. It is unlikely that many SPCs have utilised this piece of legislation; in large part public authorities do attend SPC meetings. However, it does mean that an SPC should not shy away from inviting public authorities to attend their meetings, and a formal reporting mechanism can be used should they not attend.

\section{Annual work programme}

The guidelines for establishment and operation of SPCs notes that 'each SPC should have an annual work programme and the work programme should be linked to the local authority's corporate plan' (Department of Housing, Local Government and Heritage, 2014, p. 12). It is important that each SPC has an annual work programme in place and that it is reviewed at SPC and corporate policy group (CPG) meetings to assess progress.

\section{Corporate policy group - A mini cabinet}

The council's CPG is made up of the cathaoirleach of the council along with the chairpersons of each SPC. The operational guidelines state that 'the CPG links the work of the different SPCs, acts as a sort of cabinet and provides a forum where policy positions affecting the whole council can be agreed for submission to the full council' (Department of Housing, Local Government and Heritage, 2014). It is important that CPGs are operating effectively. Callanan (2005, p. 920) states that the intention behind the CPG was 'to create an embryonic "cabinet-style" structure within Ireland's local government'. As a cabinet the cathaoirleach and SPC chairpersons, on behalf of their committees, should drive the council's policy agenda.

The suggestions of training for SPC members, utilising existing legislation, and ensuring a robust annual work programme and a strong CPG can help in ensuring that SPCs allow for more input for elected members and sectoral interests in the policymaking process. Forde (2005, p. 146) acknowledges this, noting 'if operated effectively, SPCs could become one link in a policy-making chain that could 
stretch from local right up to national level, involving citizens, local and national elected representatives and officials'. However, until there is a significant transfer of power from central government to local authorities over policy, it is difficult to see how SPCs offer 'full involvement in the policy-making process from the early stages, when policy options are more fluid', as outlined in the operational guidelines for SPCs.

\section{Conclusion}

The legislation, operational guidelines and schemes of SPCs, in theory, offer a 'full involvement' in the policymaking cycle for elected members and sectoral interests. However, as examined in this paper, there are a number of key challenges, including conflict between elected representatives and sectoral interests, lack of engagement in the process and the strong centralisation of Irish local government, which mean in practice that SPCs are not having 'full involvement' in the policymaking cycle. Recommendations around the training of members, using what powers SPCs do have, and adopting a robust annual work programme and a strong CPG can alleviate the challenges. However, unless there is a transfer of power from the centre to the local, SPCs will struggle to be truly active participants in local policy development.

\section{References}

Barrington, T. (1993). The civic deficit in Ireland. In M. O'Connell (Ed.), People power. Dublin: Institute of Public Administration.

Callanan, M. (2005). Institutionalizing participation and governance? New participative structures in local government in Ireland. Public Administration, 83 (4), 909-29.

Department of Housing, Local Government and Heritage. (2014). LG 07/2014 Establishment of new strategic policy committees (SPCS). Retrieved from http://www.housing.old.gov.ie/sites/default/files/publications/files/lg_07__2014_circular_est_of_spcs_and_cpg_-_spc_guidance.pdf [1 November 2020].

Dublin City Council. (2020). Agenda - Economic Development and Enterprise SPC 10 November 2020. Retrieved from https://councilmeetings. dublincity.ie/documents/g4162/Agenda $\% 20$ frontsheet $\% 2010$ th-Nov$2020 \% 2015.30 \% 20$ Economic $\% 20$ Development $\% 20$ and $\% 20$ Enterprise $\% 2$ 0SPC.pdf?T $=0$ [7 June 2021]. 
Fesler, J., \& Kettl, D. (2008). The politics of the administrative process (4th ed.). Washington, DC: CQ Press.

Forde, C. (2005). Participatory democracy or pseudo-participation? Local government reform in Ireland. Local Government Studies, 31 (2), 137-48.

Gannon, G. (2014, 28 February). SPC members disappointed with experience on committee. Mayo Advertiser. Retrieved from https:/www.advertiser.ie/ mayo/article/67407/spc-members-disappointed-with-experience-oncommittee [15 March 2021].

Hague, R., \& Harrop, M. (2010). Comparative government and politics (8th ed.). London: Palgrave MacMillan.

Kilkenny County Council. (2016). Minutes of strategic policy committee 2 Infrastructure policy, transportation, fire and emergency services issues held in County Hall on Friday 2 September 2016. Retrieved from https://www.kilkennycoco.ie/eng/your_council/council_meetings/social_str ategic_policy_committee_meetings/2016/[30 November 2019].

Louth County Council. (2019). Strategic policy scheme (SPC) 2019-24. Retrieved from https://www.louthcoco.ie/en/louth_county_council/com mittees_of_council/strategic_policy_committees/strategic-policy-scheme2019-20241.pdf [20 April 2021].

Meath County Council. (2019). Draft strategic policy committee scheme 20192024. Retrieved from https://consult.meath.ie/ga/system/files/materials/ 127/Draft \%20Strategic\%20Policy\%20Committee\%20Scheme\%202019_2 024_0.pdf [20 April 2021].

Quinn, B. (2007, 14-15 February). People, policies and participation in Irish local government: Aspirations, ambitions and ambiguity. Paper presented at the CINEFOGO Conference Citizen Participation in Policy Making, The Create Centre, Bristol.

Wexford County Council. (2018). Planning \& Building Control SPC minutes of meeting of 15 November, 2018. Retrieved from https:/www.wexfordcoco.ie/ sites/default/files/content/CouncilDemocracy/SPCMinutes/Minutes-ofSPC-Meeting-15-Nov-18.docx [7 June 2021].

Wexford County Council. (2019). Planning \& Building Control SPC minutes of meeting of 6 March, 2019. Retrieved from https://www.wexfordcoco.ie/ sites/default/files/content/CouncilDemocracy/SPCMinutes/Minutes-ofMeeting-06.03.19.docx [10 November 2021]. 